\title{
Experiences with the use of stabilisation geogrids in demonstrating an improvement in bearing capacity of recycled materials
}

\author{
P. Mazurowski \\ Tensar Polska Sp. z o.o., Gdańsk, Poland \\ K. Zamara \& C. Gewanlal \\ Tensar International Ltd., Blackburn, UK \\ J. Kawalec \\ Technical University of Silesia, Gliwice, Poland
}

\begin{abstract}
The use of recycled granular materials for road construction should be a necessity in current times; both for economic and environmental reasons. By the use of such materials, the road construction industry helps to protect natural resources and reduce its carbon footprint, while lowering the cost of pavement construction. However, the use of recycled materials can often raise concerns, viz. design compliance, low homogeneity, perceived lower quality and an onerous production process when compared to the use of virgin materials. It may be common practice for the variability in the engineering parameters of these materials to influence designers to specify thicker pavement layers in order to ensure that the required bearing capacity and/or design life of the road is achieved.

The use of hexagonal stabilisation geogrids may provide a method of mitigating against the loss of homogeneity and improve the engineering parameters of recycled granular materials. The case-studies presented herein demonstrate that the mechanical stabilisation of recycled granular materials with a hexagonal geogrid, results in an increased stiffness of the layer and significantly aids compaction. When aggregate is placed and compacted on a stiff hexagonal geogrid, aggregate particles interlock within the geogrid apertures and are confined by its stiff ribs. A composite mechanically stabilised layer (MSL) is created, in which the geogrid and aggregate act in unison. Lateral restraint, provided by the geogrid, reduces strain within the aggregate skeleton and thereby increases the stiffness of the layer. The result is that the required performance parameters, be it a bearing capacity of a layer and/or life of the pavement, can be successfully achieved with the use of, and possible reduction in the required layer thickness of, recycled granular materials.

The concept of mechanical stabilisation of aggregate layers by the use of geogrids is detailed in this paper. Furthermore, several case studies are presented which demonstrate the use of hexagonal stabilisation geogrids to improve the bearing capacity of various recycled materials such as recycled asphalt, recycled concrete, and coal mine shales.
\end{abstract}

Keywords: Recycled aggregate, hexagonal geogrid, mechanical stabilisation, recycled asphalt, RA 


\section{INTRODUCTION}

Construction and demolition waste (CDW) accounts for approximately 25\% - 30\% of all waste generated in the EU (European Commission, 2019). Currently, the level of recycling of CDW varies in different countries, ranging from 10 to $90 \%$. The goal of the EU is to reach a minimum $70 \%$ level of recycling by the end of 2020 .

According to Symonds, 2019 "the largest single consumer of aggregates in most Member States is the road construction industry". There are a lot of economic and environmental benefits associated with the use of recycled aggregates in the road construction industry.

Arguably the most important environmental benefit is resource conservation. As the availability of virgin aggregate material becomes limited, every opportunity to reduce its use generates financial and environmental benefits. Another benefit is a substantial reduction of greenhouse gas emissions, obtained due to reduced transportation and energy consumption. Recycling can eliminate the need for disposal of hazardous debris, like old asphalt with tar; these can be utilized in mixes with cement and bitumen emulsion instead. As recycled material does not have to be disposed to landfill, recycling helps to preserve landfill capacity. Recycling also helps with conservation of the landscape - both by avoiding the creation of new stockpiles of demolition rubble and by negating unsightly changes to the landscape cased by quarrying of virgin aggregates.

Significant economic benefits can be realised through the reduction of material, plant and labour project costs. Snyder et al. 2018 gives examples of several projects showing substantial savings achieved due to the use of recycled concrete; one such project achieved as much as $5 \$$ million in savings. Cost reduction results not only from the lower price of recycled aggregate (which is not always the case), but also from reduced haul distances, construction program and disposal costs. Haul distance can be reduced because in most cases the recycling facility is located much closer to the construction site than any virgin aggregate quarry. In the case of certain materials, such as concrete and asphalt, it is also possible to recycle these on site, eliminating the need for haulage completely. The reduction in haul distance, material volumes and construction time results in reduced damage to existing access roads. A secondary benefit is the reduced negative impact that construction activities often have on local communities VIZ. travel time increase, noise, dust, and plant exhaust fume emissions to name a few.

The use of hexagonal stabilisation geogrids can add further benefits to projects by improving the effective engineering properties of recycled aggregates and thereby enabling the use of reduced layer thicknesses while achieving comparable performance of pavements.

\section{AGGREGATE STABILISATION WITH HEXAGONAL GEOGRID}

\subsection{Concept of stabilisation with geogrid}

Geogrids in civil engineering structures have been used for decades. The intended use of geogrids is to mechanically stabilise granular layers in order to minimise deformation during trafficking, to improve the load-bearing capacity and to increase the design life of roads. The combination of the geogrid and aggregate creates a mechanically stabilised composite layer with significantly improved properties and performance capabilities in response to dynamic and static loading when compared with the aggregate layers alone.

Research on the effect of geogrids on pavements aggregate began over 30 years ago. Early research at Oxford University dated in the late 70 s and 80 s investigated mechanisms of geogrid's improvement of aggregate layers (e.g. Milligan and Love 1984). This research in the field of geogrid mechanical stabilisation concluded that aggregate layers combined with geogrids exhibited a higher bearing capacity than those without. Further the mechanism associated with that behaviour was defined as interlock which resisted tension at the level of the geogrid. Also, the tensioned membrane effect, that these days is attributed to high strength products, was considered to have a limited effect on performance and this too only at high 
deformation levels within the fill base. The difference between the interlock/confinement mechanism and the tensioned membrane mechanism is presented in Figure 1.
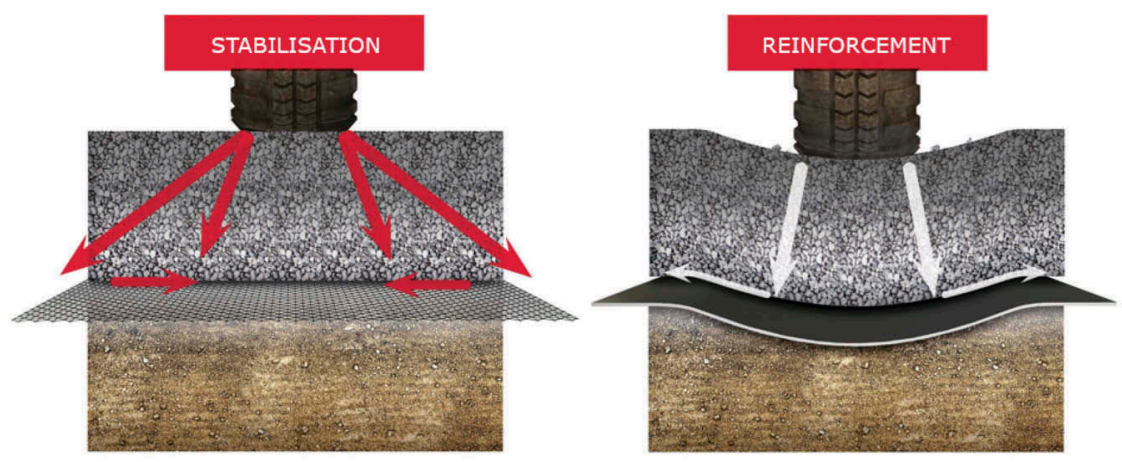

Figure 1. Mechanisms of geosynthetic support in pavement, Left: mechanical stabilisation by geogrid; Right: reinforcement at high deformation level.

Further laboratory research by Haas et al. 1988 concluded that for optimal long-term pavement performance, geogrids should operate within a zone of moderate elastic strain (i.e. 0.05 to $0.2 \%$ ) and for the overall design life this plastic strain should not exceed 1 to $2 \%$ (this being linked to pavement rutting criteria). The above conditions ensure geogrid insitu performance within its elastic limits which contributes to the effective confinement of aggregates particles.

The early and insightful research by Haas et al. created a foundation for further research and development into the field of geogrid mechanical stabilisation in pavements. The studies progressed into full scale experiments that confirmed the conclusions of laboratory studies.

Cook et al. 2016 provided a summary of published full scale trafficking trials where the mechanisms of geogrid stabilisation were investigated. A series of Transport Research Laboratory (TRL) trafficking trials were analysed and the mechanisms of geogrid stabilisation versus geogrid reinforcement were discussed. A total of eight trials undertaken in the UK TRL laboratories were summarized in the study with different geosynthetic products tested for their stabilisation performance.
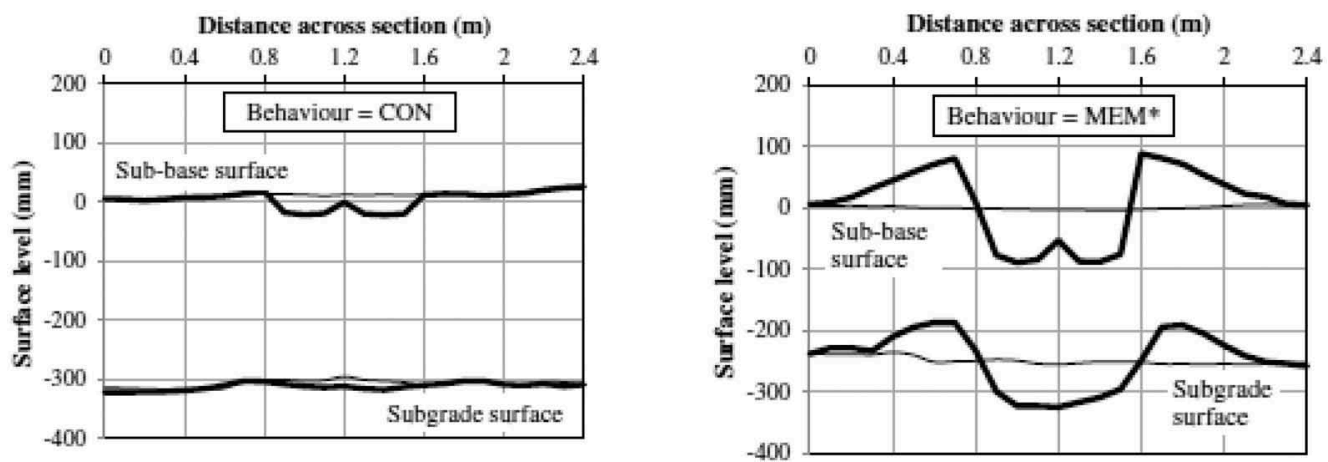

Figure 2. Transverse surface profiles, Left: full confinement ("CON"), negligible subgrade deformation; Right: full tensioned membrane ("MEM"), with surface rut and subgrade deformation of much the same size and geometry (Cook et al. 2016). 
Cook et al. 2016 analysed in detail the cross-sections of aggregate layers within the pavement structures. Deformation at surface were compared with deformations at the geosynthetic level (Figure 2). The conclusions of Cook et al. 2016 echoed the early studies of Milligan and Love 1984 and Haas et al. 1988, by attributing the benefit of geogrid inclusion to particles confinement and effective interlock. If the true stabilising mechanism is achieved, this further manifest itself in improved load distribution due to lateral restraint and reduced aggregate deterioration. Geogrids allow the aggregate to lock itself in the geogrid apertures, which results in the formation of a stiff layer at the base of the aggregate. Monitored geogrid stabilisation and reinforcement (tensioned membrane) effect is presented in Figure 2.

The strong international, scientific evidence supporting the argument of the geogrid mechanical stabilisation function (i.e. interlock and confinement) being different to the reinforcing function (i.e. tensioned membrane), resulted in acceptance of the geogrid mechanical stabilisation function definition. ISO 10318-1:2015 Amendment 1-2018 defines the geogrid mechanical stabilisation function as 'Improvement of the mechanical behaviour of an unbounded granular material by including one or more geosynthetic layers such that deformation under applied loads is reduced by minimizing movement of the unbound granular material'.

\subsection{Concept of pavement optimisation}

Aggregate layers stabilised with hexagonal geogrids have increased stiffness compared to nonmechanically stabilised layers. This influences the performance of the whole pavement and can be utilised in two ways: (1) it is possible to increase the life of a pavement compared to a non-mechanically stabilised pavement of similar thickness, and (2) it is possible to reduce the thickness of individual pavement layer(s) and achieve similar performance to thicker, nonmechanically stabilised pavements. This layer thickness reduction need not necessarily be limited to the mechanically stabilised layer; the other granular layers and even the asphalt thickness may be reduced to offset the improved performance provided by the mechanically stabilised layer. This way of using geogrids in pavements was introduced several years ago by the producer of hexagonal geogrids under the term "Pavement Optimisation".

A series of Accelerated Pavement Tests (APTs) were performed at the U.S. Army Engineering Research and Development Centre to quantify the benefits of hexagonal geogrids. Tests were conducted between 2010 and 2016, in three phases. In total, 8 sections were tested.

The granular base of test sections consisted of either 15 or $20 \mathrm{~cm}$ of crushed limestone. Four of the sections had a base layer stabilised with hexagonal geogrids. Six sections had surfacing of $5,7.5$ or $10 \mathrm{~cm}$ of dense-graded hot mix asphalt (HMA), and two sections had a double bituminous surface treatment (DBST). The subgrade consisted of locally available clay prepared to achieve a bearing capacity of either 3 or $6 \%$ CBR.

A Heavy Vehicle Simulator (HVS) device was used to traffic test sections. Sections on 3\% CBR subgrade were subjected to 100000 axle loads, while sections on $6 \%$ CBR up to 800000 axle loads. Throughout the tests, rut depth measurements were collected on all test sections.

Full tests results are presented in reports: Jersey et al. 2012, Norwood et al. 2014, Robinson et al. 2017. All sections stabilised with hexagonal geogrids substantially outperformed their non-mechanically stabilised control equivalents including the sections with thicker asphalt and/or base layers. Based on these results, modifications to pavement design methods were developed by the manufacturer of the hexagonal geogrids. Basic assumptions of the modification to the mechanistic-empirical pavement design method were presented by Mazurowski et al. 2019.

\section{RECYCLED CONCRETE AGGREGATE}

Recycled Concrete Aggregate (RCA) is one of the most used recycled aggregates in pavement construction. It is commonly used as a substitute for virgin aggregates in capping, sub-base or 
base layers. In the US, about $65 \%$ of RCA is used as aggregate base material in road construction (Snyder et al. 2018).

RCA can be produced to meet all the requirements of typical aggregate base layer specifications. This, however, affects its price - the cost of good quality RCA can be comparable to the cost of virgin aggregate (Snyder et al. 2018). Lower quality RCA, which can contain crushed bricks and other contaminations (wood, plastic etc.) is usually much cheaper, but often does not meet the requirements and its use is limited.

One possible way of improving parameters of RCA is by stabilisation with hexagonal geogrids. This is especially useful in the case of low-quality RCA.

RCA usually has lower resistance to abrasion mass loss compared to virgin aggregate (American Concrete Pavement Association, 2020). Abrasion of aggregate in pavement is a result of movement of particles under cycling loading. This can result in the deterioration of engineering parameters over time, especially in low quality RCA containing crushed bricks. Liu et al. 2017 confirmed reduction of particle movement under cycling loading in tests performed with a device called Smart Rock. It was a 3D-printed artificial stone, in which accelerometers were installed, which allowed for real time movement tracking of the stone. The device was installed within test sections (both stabilised with geogrids and control) of $25 \mathrm{~cm}$ of rail ballast loaded with $1 \mathrm{~Hz}$ frequency cyclic loading. Stabilisation of aggregate with geogrid resulted in a substantial reduction of both displacement and particle rotation under cyclic loads, and thus reduced aggregate abrasion.

Hexagonal geogrids were used in numerous projects to stabilise RCA, both high and low quality. Two case studies are described below.

Św. Ducha is a street in the historical centre of Gdańsk, Poland; in an area known for poor insitu soil conditions. It was constructed on a subgrade of non-controlled embankment fill consisting of different soils with the addition of organic soils and debris from buildings damaged during WWII.

The original design of the reconstructed pavement included a layer of crushed aggregate stabilised with a hexagonal geogrid and a layer of cement stabilised sub-base material. The addition of a second layer of hexagonal geogrid allowed for optimisation of the pavement, which resulted in a thickness reduction of $5 \mathrm{~cm}$ of the base layer, removal of cement stabilised subbase, and substitution of virgin crushed aggregate caping layer with RCA (Figure 3). This resulted in substantial savings for the contractor, who had a big quantity of good quality RCA available from another nearby construction site.

Hexagonal geogrids were used to stabilise unpaved access roads to Kretinga Wind Farm in Lithuania Figure 5. Roads were constructed in areas of low bearing capacity soils, and were required to handle traffic of trucks carrying aggregate, concrete, cranes and turbine parts.
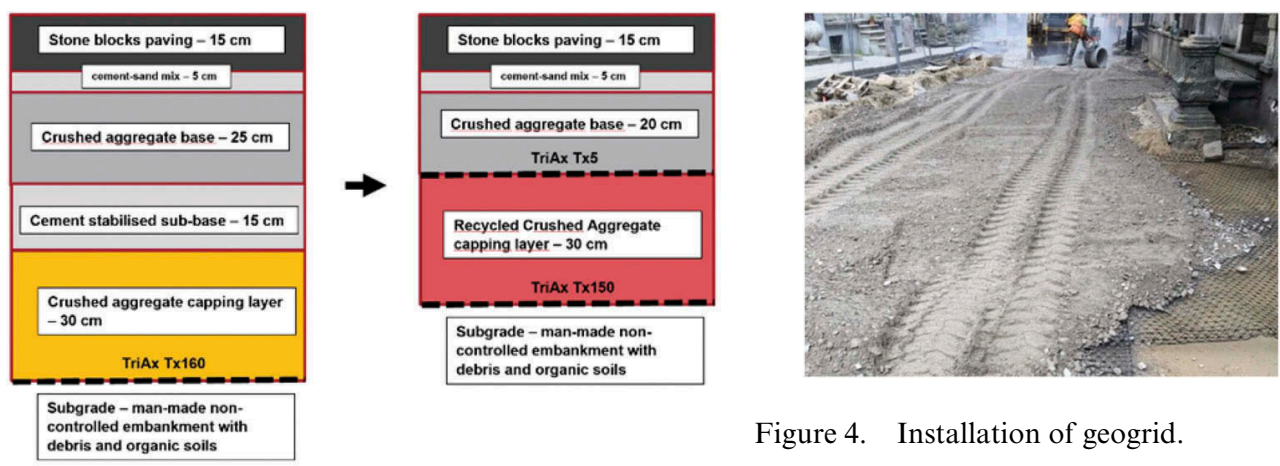

Figure 4. Installation of geogrid.

Figure 3. Original and optimised structure. Tx 5 , Tx 150 and Tx160 describe different geogrids types. 
Locally available RCA was used to construct the pavements. The RCA was of a very low quality, with high content of crushed bricks. The use of hexagonal geogrids not only allowed for the installation and compaction of the RCA aggregate on weak soils, but also for the reduction of the thickness of the pavements.

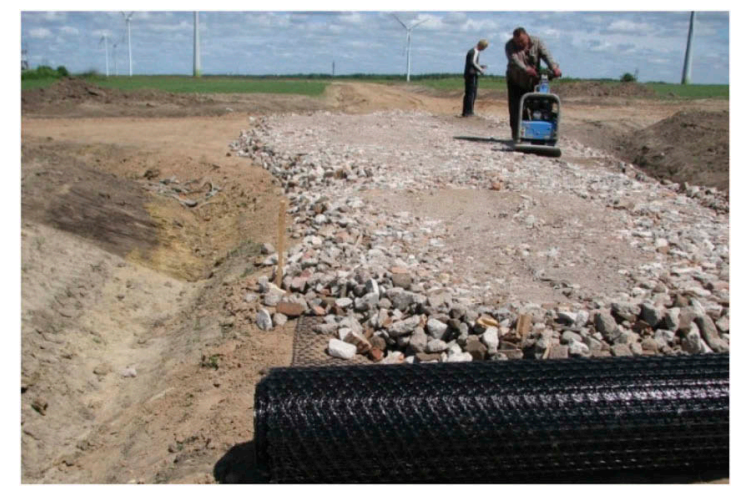

Figure 5. RCA layer stabilised with hexagonal geogrid at Kretinga Wind Farm.

\section{COAL MINE SHALES}

Deep coal mining results in the production of large volumes of waste material stored in large heaped stockpiles. As coal is typically interlayered with other type of soft rock, once brought to the surface special mechanical processes are implemented to separate the coal from the lowcalorie material which cannot be used for energy production. Currently environmental aspects are forcing most coal producers to reduce/eliminate such type of fuel from energy production, but historical mining activities have already resulted in billions of tons of excavated material being stockpiled.

In most cases, coal mining waste consists of clay coal shales. Natural coal shales are not frost resistant and as such cannot be used within the frost depth of any engineering structure. However due to their good mechanical properties and ease of compaction they are often used to form lower parts of road embankments as depicted in Figure 6.

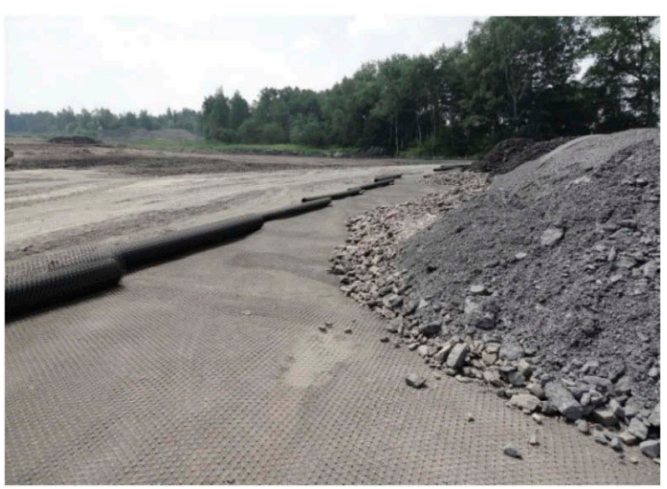

Figure 6. Stabilisation of expressway embankment base constructed from unburnt clay shales - Road 902 project in Gliwice.

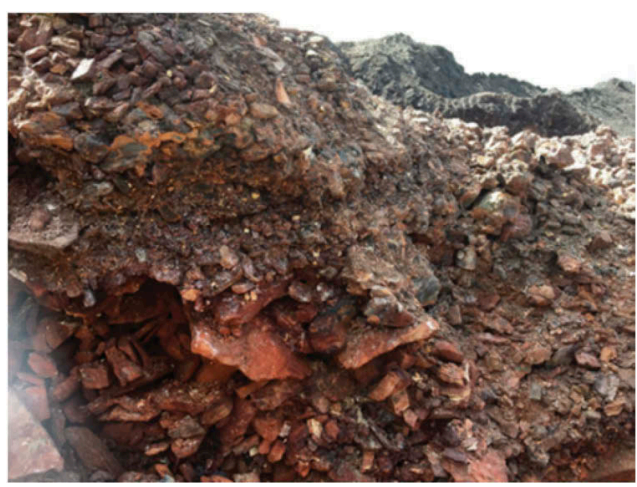

Figure 7. Typical burn coal shale stored in an open heap during excavation. 
Storage in high, loose heaped stockpiles (uncompacted, especially during the early days of mining when no compaction equipment was available) often resulted in self-ignition. If temperatures in the stockpile reached over $700-800{ }^{\circ} \mathrm{C}$, the clay shales became a fully burnt red coloured material of different physical and mechanical properties as depicted in Figure 7 . The material becomes frost resistant and as such is acceptable for use within the frost dept of the road structure (subbase and base). Secondly, due to its low cost and the large volumes available, it becomes a preferred material by Contractors wanting to keep their project budgets within limits. Coal mine shales stabilised with hexagonal geogrids were used in numerous road projects in Silesia, Poland over the last 12 years. Some examples of these are depicted in Figures 8 and 9.

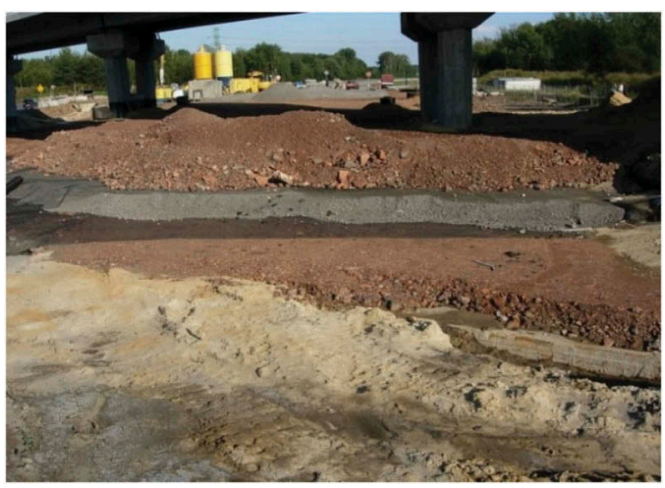

Figure 8. Example of geomattress with two layers of burnt coal mining shales (red colour) under motorway pavement - A1 motorway project in Zabrze.

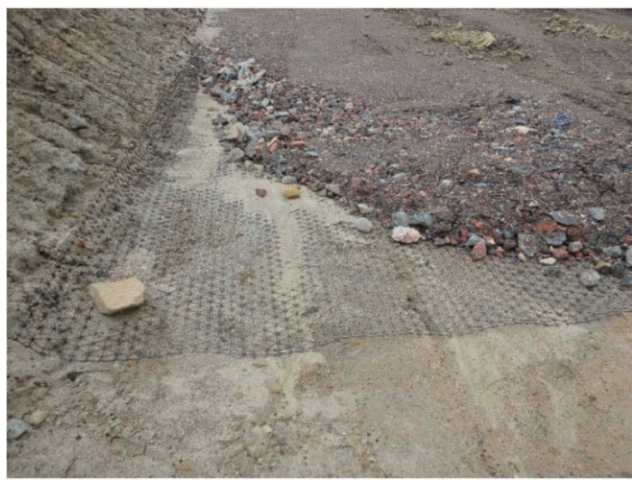

Figure 9. Example of mining waste layer stabilised by geogrid for road construction - road 86 project in Katowice.

\section{RECYCLED ASPHALT}

Two rehabilitation projects in South Africa have shown that the stabilisation effect produced by hexagonal geogrids can also be realised with the use of bound treated base materials. Recycled asphalt and granular base materials were used in these projects to save time, money and the environment. The Harvey and Hanger Roads project was constructed in Bloemfontein in 2012 and used a bitumen stabilised material (BSM) base with $25 \%$ milled recycled asphalt in the mix design. The McGregor Street project was constructed in Bloemfontein in 2016 and used a BSM foam base with 30\% milled recycled asphalt and 60\% milled granular base/subbase materials. Both mix designs are detailed in Table 1.

Table 1. BSM mix designs for Harvey and Hangar Roads as well as McGregor Street.

\begin{tabular}{ll}
\hline Harvey and Hangar Roads & McGregor Street \\
\hline - $75 \%$ Natural crushed stone; & - $30 \%$ Recycled asphalt surfacing \\
- $25 \%$ Recycled asphalt surfacing; & - $20 \%$ Milled crushed stone base \\
- $2.5 \%$ Bitumen (SS60 emulsion); & $-40 \%$ Milled gravel subbase \\
- $1.2 \%$ Cement & - $10 \%$ Imported crushed stone \\
& - $1 \%$ Cement \\
\hline
\end{tabular}


As both projects are busy arterial roads carrying in excess of 10,000 vehicles per day, the traffic disruption needed to be minimized (Raman, 2017). The ground investigations revealed the occurrence of large hard packed stone in some sections, like a Macadam pavement. The railway station that Harvey Road serves was completed in 1890. The type of Macadam pavement in sections of Harvey and Hanger Roads most probably dated back to the early 1900's (Pretorius et al. 2013). The most significant site constraint was that all the sites had shallow services at a depth of roughly $300 \mathrm{~mm}$ beneath the existing surface. The analyses for these roads produced a required repair depth well in excess of the depth of the existing services.

Being located in the midst of a well-established Central Business District with existing drainage, kerbs and shop entrances, the existing surface level could not be raised. The stabilisation factor produced by the use of a hexagonal geogrid with a bound bitumen modified base was therefore utilised to provide the required performance at a depth which did not disturb the existing services. The pavement layerworks designs, showing the theoretical traffic carrying capacity in terms of Million Equivalent Standard Axle Loads (MESAL's), are depicted in Figure 10.
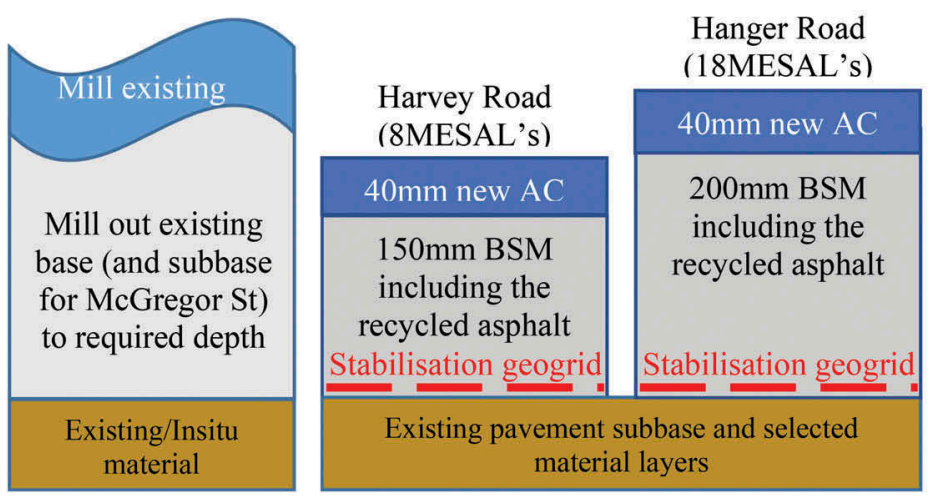

\begin{tabular}{|c|}
$\begin{array}{c}\text { McGregor Street } \\
\text { (17MESAL's })\end{array}$ \\
\hline 40mm new AC \\
\hline $\begin{array}{c}\text { 250mm BSM } \\
\text { including the } \\
\text { recycled asphalt } \\
\text { and reclaimed } \\
\text { crushed stone } \\
\text { base }\end{array}$ \\
Stabilisation geogrid \\
\hline Insitu roadbed \\
material
\end{tabular}

Figure 10. Layerworks designs.

Harvey and Hangar Roads: Prior to rehabilitation the existing pavements showed severe signs of distress and, at the time of analysis, had no residual life. After 8 years in service after reconstruction, both roads show only limited signs of deterioration.

Some of the milled granular base material was reused as base materials in the pedestrian sidewalks and the remainder was stockpiled by the Client for use on future projects; there was thus very little spoil generated in this project. The bitumen emulsion stabilised material was mixed and stockpiled off-site due to the site constraints of the busy built-up area. A pug mill was specially designed for this project with the ability to be used thereafter for similar applications or for pre-coating of aggregates in sealing applications.

The construction sequence for Harvey and Hangar Road is depicted in Figures 11 to 14. 


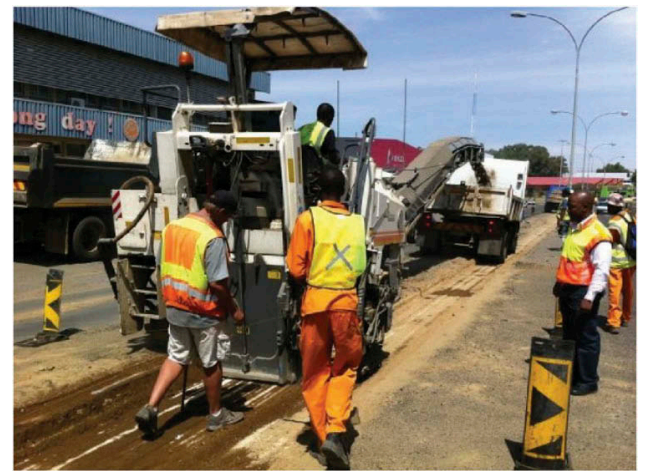

Figure 11. Milling existing asphalt.

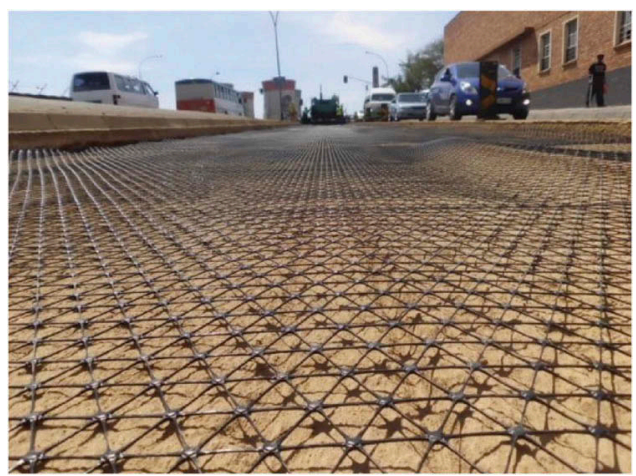

Figure 12. Installation of stabilisation geogrid.

McGregor Street: Prior to rehabilitation, McGregor Street exhibited signs of fatigue and crocodile cracking as depicted in Figure 15. At the time of analysis, the road had a residual life of 0.2 to 0.7 MESAL's which equated to 1 to 2 years.

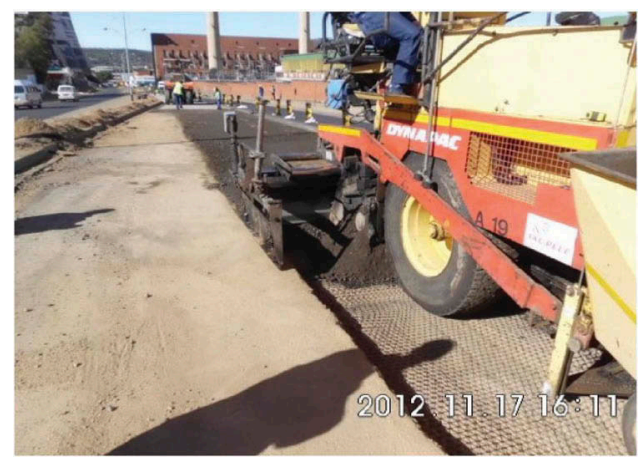

Figure 13. Installation of BSM with paver.

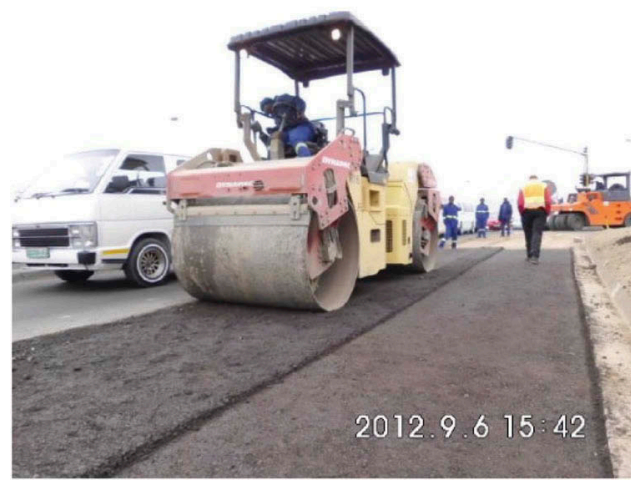

Figure 14. Rolling of base.

McGregor Street after reconstruction shows no sign of deterioration after some 4 years in service as depicted in Figure 16. The construction sequence for McGregor Street was similar to that of Harvey and Hangar Roads depicted in Figures 11 to 14.

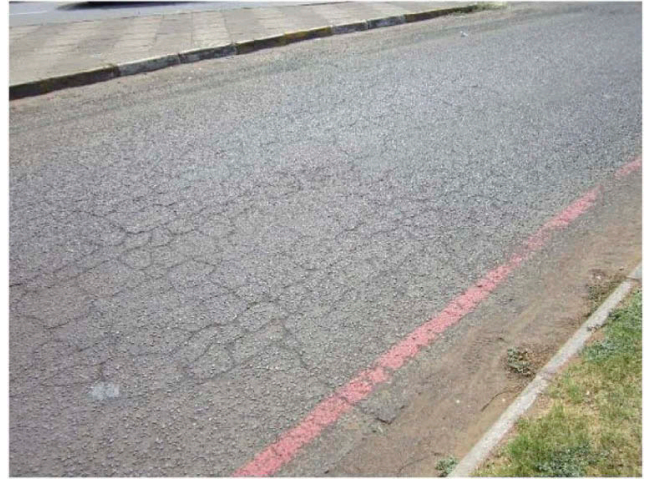

Figure 15. McGregor Street prior to rehabilitation.

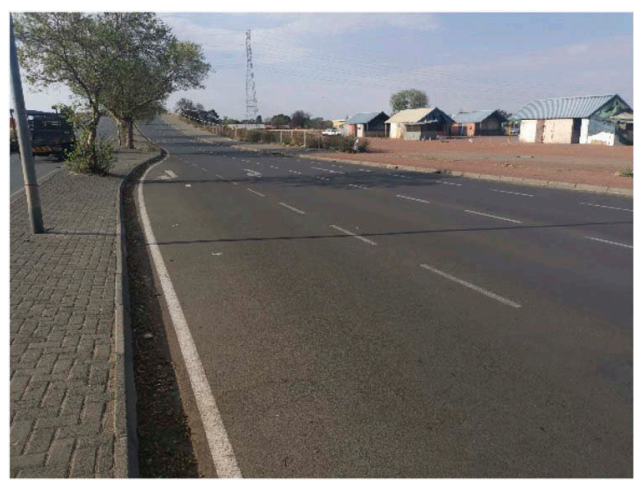

Figure 16. McGregor Street in 2020. 
The McGregor Street project maximized the use of recycled milled materials. These were sorted and tested in a laboratory to optimize the performance of the pavement. Ultimately only $10 \%$ of imported crushed stone was required as mentioned in Table 1.

The BSM1 foam was mixed in-plant using a high-quality mobile mixer and allowed for up to 5 days of stockpiling before placing on the hexagonal geogrid using a paver.

\section{CONCLUSIONS}

The use of recycled aggregate brings numerous benefits, both economic and environmental, to the road construction industry. Stabilisation of aggregate with hexagonal geogrids is a way to maximize these benefits, by reducing the volume of good quality aggregate required or increasing the performance of low-quality aggregates. Extensive research carried out over the last 30 years and numerous successful case studies have confirmed the beneficial effects of stabilisation on both virgin and recycled aggregates in pavement construction. Engineers may be reluctant to use recycled asphalt because they doubt the uniformity of the material. Mechanically stabilisation of recycled asphalt by hexagonal geogrids not only enhances its engineering properties (this is known as the modulus increase effect) but also improves its uniformity. Layer thickness reduction by a factor of 1.5 to 2 times (known as the stabilisation factor) can be achieved without any loss of pavement performance by incorporating hexagonal geogrids into the layerworks design. Therefore, less recycled and/or imported fill as well as less cut to spoil of insitu material is required, resulting in cost savings.

\section{REFERENCES}

American Concrete Pavement Association website Wikipave, 2020, Recycling Concrete Pavements website http://wikipave.org/index.php?title=Recycling_Concrete_Pavements\&oldid=8728

Asphalt Academy, 2009.TG2, Technical Guideline, Bitumen Stabilised Materials. Committee of Land Transport Officials, Pretoria, South Africa: Department of Transport, South Africa, 1988, February, Draft UTG3 Structural Design of Urban Roads. Urban Transport Guidelines

Cook, J., Dobie, M., Blackman, D., 2016. The Development of APT Methodology in the Application and Derivation of Geosynthetic Benefits in Roadway Design J.P. Aguiar-Moya et al. (eds.), The Roles of Accelerated Pavement Testing in Pavement Sustainability, DOI 10.1007/978-3-319-42797-3_17C Springer International Publishing Switzerland 2016

European Commission, 2019, Environment website: https://ec.europa.eu/environment/waste/construc tion_demolition.htmBrussels, Belgium.

Haas R, Walls J and Carroll RG 1988 Geogrid Reinforcement of Granular Bases in Flexible Pavements; Transportation Research Record 1188

ISO 2015. Geosynthetics - Part 1: Terms and definitions 10318-1:2015 Amendment 1-2018. ISO/TC 221 Geosynthetics.

Jersey, S.R., Tingle, J.S., Norwood, G.J., Kwon, J. and Wayne, M., 2012. Full-Scale Evaluation of Geogrid-Reinforced Thin Flexible Pavements. Transportation Research Record, Journal of the Transportation Research Board, No. 2310, TRB of the National Academies, Washington, USA

Liu, S., Huang, H. and Qui, T. Kwon J., 2017. Comparative Evaluation of Particle Movement in a Ballast Track Structure Stabilised with Biaxial and Multiaxial Geogrids. Transportation Research Record: Journal of the Transportation Research Board, No. 2607, 2017

Mazurowski, P., Buckley, J., Kawalec, J., 2019, Modification of mechanistic-empirical pavement design method to incorporate the influence of hexagonal stabilisation geogrids. AAPA International Flexible Pavements Conference, 18th, 2019, Sydney, Australia

Milligan, G., Love, J.P., 1984. Model testing of geogrids under an aggregate layer on soft ground. Polymer Grid Reinforcement: Proceedings of a Conference Sponsored by the Science and Engineering Research Council and Netlon Ltd, London 22-23 March 1984

Norwood, G.J. and Tingle, J.S., 2014. Performance of Geogrid-Stabilised Flexible Pavements. Final Report. EDRC/GSL TR-14-28. U.S. Army ERDC, USA

Pretorius, V., Deetlefs, J., Leeuw, O., Roe, T., 2013. Innovation In Overcoming Road Rehabilitation Challenges Faced In An Urban Environment: An In-Depth Case Study.; Proceedings of the 32nd Southern African Transport Conference, Pretoria, South Africa. 
Raman, C., 2017. Utilising Bitumen Stabilised Material And A Triaxial Geogrid In The Rehabilitation Of A Busy Urban Arterial. Proceedings of the $81^{\text {st }}$ Institute of Municipal Engineers of South Africa Conference, Gauteng, South Africa.

Robinson, W.J., Tingle, J.S., and Norwood, G.J., 2017. Full-Scale Accelerated Testing of Multi-Axial Geogrid Stabilised Flexible Pavements. Draft Final Report. EDRC/GSL TR-17-X. U.S. Army ERDC, USA

Snyder, M. B., Cavalline, T. I., Fick, G., Taylor, P. and Gross, J., 2018. Recycling Concrete Pavement Materials: A Practitioner's Reference Guide. National Concrete Pavement Technology Center, Iowa State University, Ames, US.

Symonds, ARGUS, COWI, PRC Bouwcentrum, 1999. Construction and Demolition Waste Management Practices, and Their Economic Impacts. Report to DGXI European Commission. 